CRÍTICA, Revista Hispanoamericana de Filosofia

Vol. XXIV, No. 70 (abril 1992): 17-64

\title{
LA REDUCCIÓN ONTOLÓGICA Y SUS PROBLEMAS
}

\author{
Francisco RodRícuez CONSUEGRA \\ Departamento de Lógica, Historia y Filosofía de la Ciencia \\ Universidad de Barcelona
}

\section{Introducción}

El presente trabajo tiene por objetivo básico llevar a cabo un estudio crítico de la teoría de la reducción ontológica tal y como ésta ha sido presentada por Quine. El propósito inicial fuc rcdactar unas cuantas páginas que sirviesen como preludio y contexto general a un estudio sobre las ideas de Bcnacerraf sobre la reducción matemática (véase mi 199lb), pero al llevarlo a cabo efectivamente comprobé que las ideas de Quine al respecto tenían mayor importancia de lo que pensé en un principio. Y ello no ya sólo por su interés intrínseco, sino también porque, estudiadas en su contexto histórico, es decir, en el marco del logicismo clásico y la teoría de conjuntos subsiguiente, arrojan luz sobre la rclevancia ontológica de la reducción matemática y sobre la rclevancia linguística de los problemas ontológicos. Asimismo, las críticas que ha suscitado la doctrina quineana de la reducción ontológica contribuyen decisivamente a poner de manifiesto los problemas que subyacen a todo intento de identificar reducción y eliminación.

En lo que sigue, ensayo primero una presentación general dc la filosofía quineana donde, para mi sorpresa, he podido presentar todas sus tesis cólebres como simples consccuencias del compromiso ontológico: el famoso "ser es ser el valor de una variable" (sección 2), para pasar después a un estudio evoluti- 
vo donde muestro que la propia profundización de la doctrina de la relatividad ontológica ha estado en función de la clarificación de las dificultades de la reducción matcmática —que señalo-, en parte como consecuencia de una cierta falta de consideración por los problemas del logicismo clásico de Frege y Russell (secciones 3 y 4). Por último, paso revista a las críticas de las ideas quineanas sobre la reducción ontológica que aparecen en trabajos posteriores y me esfuerzo por sacarles partido dentro de mi enfoque general, destacando especialmente la dificultad de sentar una doctrina de la reducción con independencia de un cierto absolutismo en ontología, así como de un cierto "empirismo" en matemática, donde a veces la adopción de determinada reducción es preferible a otra por motivos de "fertilidad".

\section{La unidad de la filosofía quineana}

La tesis del compromiso ontológico de Quine parte de su extensión de la tcoría de las descripciones de Russell, que eliminaba sólo algunos tćrminos singulares, a todos ellos. La maniobra fue llevada a cabo aplicando la idea originaria de Russell, no a descripciones, sino a abstractos en general ("los ... tales que..."), y cxplicando a continuación las descripciones como abreviaturas dc abstractos (1940a, § 26, p. 155). Después, los nombres, y todas las expresiones que se comporten como tales, sc asimilan a abstractos, es decir, se interprctan como abreviaturas de descripcioncs, lo que equivale a considerar las variables como matrices de nombres. La conclusión contiene ya los clementos de toda la filosofía quineana postcrior: "Desde el punto de vista de nuestra notación primitiva nuestros únicos términos son variables, pronomibres; todos los abstractos, y en particular todos los nombres, son últimamente susceptibles de climinación" (1940a, § 27, p. 161). ${ }^{1}$ La tesis del compromiso

1 Quine plantea su eliminación de los nombres como un elaro avance sobre Russell, quien, aunque adṇitió la climinación contextual de algu- 
ontológico, implícita ya en esta maniobra, fue formulada con toda claridad muy poco después (1943a, p. 128): ${ }^{2}$

Las operaciones de generalización existencial y de aplicación suponen maneras de usar el sustantivo que nos obligan a reconocer la existencia de un objeto designado por él. La ontología con la cual nos compromete el uso del lenguaje abarca smplemente los objetos que consideramos como pertenecientes al ámbito de nuestros cuantificadores, es decir, dentro del dominio de valores de sus variables.

Similares formulaciones tienen lugar en 1948a (p. 39): "Todo lo que puede decirse con la ayuda de nombres puede decirse también en un lenguaje que no los tenga. Ser asumido como entidad significa pura y simplemente ser asumido como valor de una variable"; y en 1952a ( $(42$, p. 303): "Los objetos cuya existencia implique nuestro discurso son en definitiva los objetos que deben admitirse como 'valores de las variables' a los efectos de la verdad de nuestros asertos; en particular, son los objetos que hay que incluir en la totalidad de aquellos por considerar en las interpretaciones de nuestras variables de cuantificación. Ser es ser el valor de una variable."

nos supuestos términos singulares, aquellos que carecían de referencia, mantuvo los nombres propios en general: "Russell no dio, sin embargo, el paso ulterior de considerar que todos los nombres eran descripciones para eliminarlos también. Prefirió conservar una distinción epistemológica entre nombres que eran meras abreviaturas de descripciones y nombres que eran propios e irreductibles a descripciones, y que se aprendían por confrontación directa con lo que nombraban" (1952a, § 42, p. 303-304). Lo que no ve Quine es que Russell estaba obligado a ello pues, por miedo al idealismo de Bradley, quien había ya adelantado la tesis de que todos los nombres son descripciones disfrazadas (véanse mis $1989 \mathrm{~b}$ y $1990 \mathrm{a}$ ), neccsitaba un punto de apoyo firme en los nombres propios como signos de sujetos lógicos absolutos.

2 En realidad la célebre tesis quineana había aparecido ya cuatro años antes, como me corrige con benevolencia el propio profesor Quine: "The universe of entities is the range of values of variables. To be is to be the value of a variable" ("Designation and existenee", Jrn. Philos., no. 36, 1939, pp. 701-709, prineipalmente p. 708). 
El paso siguiente en importancia es la tesis de la relatividad ontológica, con toda su cohorte de subtesis que confluyen en el holismo teórico (indeterminación de la traducción, inescrutabilidad de la referencia, etc.). Pues bien, aunque la tesis explícita no fue formulada sino hasta 1969 , creo que se la puede considerar ya presente a través de la idea de que la referencia no cursa ya por medio de nombres, sino por medio de predicados y las consiguientes estructuras cuantificacionales, que es una consecuencia de la anterior eliminación. En efecto, decir que los términos singulares desaparecen es decir que cualquier referencia a objetos debe operar a través de las variables de cuantificación. En otras palabras, decir que ser es ser el valor de una variable es decir que ser es ser aquello a lo que se refiere una variable, que gramaticalmente puede considerarse, según Quine, como un pronombre: "Los pronombres son los medios de referencia básicos [...] se nos hará convictos de una detcrminada suposición ontológica si y sólo si el supuesto aducido ticne que encontrarse entre las entidades que constituyen cl campo de nuestras variables para que una de nuestras afirmaciones resulte verdadera" (1948a, p. 39).

Por tanto, cl compromiso ontológico lleva a la relatividad ontológica por cuanto tal compromiso determina la ontología con la que una determinada forma de hablar, o tcoría, está compromelida de hecho. Así, si hemos de escoger entre diversas ontologías sólo podremos hacerlo abriendo una distinción entre "lo que hay" en general y "lo que una tcoría dice que hay" (1948a, p. 43). Ello no debe suponer que "lo que hay" sea una cuestión meramente lingüística, aunque sí que se trata de un asunto relativo a una ontología, que está siempre determinada por una forma de hablar, es decir, por un esquema eoneeptual con el que nos compromete nuestra forma de hablar. Ese es el sentido de la tesis de que "nuestra aceplación de una ontología es en principio análoga a nuestra accptación de una teoría cientílica", es decir, de un esquema conceptual que nos permita abarcar y ordenar la experiencia (1948a, p. 44): 
Nuestra ontología queda determinada en cuanto fijamos el esquema conceptual más general que debe ordenar la ciencia en el sentido más amplio; y las consideraciones que determinan la construcción razonable de una parte de aqucl csquema conceptual —la parte biológica, por ejemplo, o la física- son de la misma clase que la consideraciones que detcrminan una construcción razonable del todo. Cualquiera que sea la extensión en la cual puede decirse que la adopción de un sistema de teoría científica es una cuestión de lenguaje, en esa misma medida -y no más- puede decirse que lo es también la adopción de una ontología.

Lo cual es como decir que las discrepancias ontológicas lo son, real e inevitablemente, de esquemas conceptuales, es decir, en última instancia del campo referencial quc admitimos para nuestras variables de cuantificación. De ahí el nexo quc señalaba más arriba. La relatividad ontológica es una tesis más amplia; requiere, además, decir claramente que las cucstiones de referencia remiten siempre a un lenguaje de fondo, así como añadir que entender un idioma o una teoría no es sino pasar de un idioma a otro, de una teoría a otra, lo que equivale a traducir sus correspondientes ontologías. Pero, como ya sabemos, esto puede hacerse sólo determinando un campo referencial: diciendo qué objetos configuran el universo de nuestro discurso, lo que no es más que asignar un campo de valores a nuestras variables de cuantificación. ${ }^{3}$

3 Parece que el progreso quineano pasó, en este punto, por las ideas de Carnap, especialmente por las relativas a su distinción de 1950a entre cuestiones internas y externas a un lenguaje, junto a su idea de los marcos lingüísticos (aunque naturalmente Carnap estaba por entonces ya al cabo de la calle de la anterior formulación quineana). Sin embargo el punto de vista de Quine era ya entonces más amplio, por abarcar también cualquier teoría científica, es decir, incluyendo también las ciencias empíricas: "Camap maintains that ontological questions and likewise questions of logical or mathematical principle, are questions not of fact but of choosing a convenient conceptual scheme or framework for seience; and with this I agrec only if the same be coneeded for every scientific hypothesis" (1951b, pp. 71-72). Naturalmente aquí esıaba ya trabada la indistinción analítico- 
También la tesis de la indeterminación de la traducción, vía traducción radical de un idioma desconocido, se infiere directamente de la eliminación cuantificacional de los términos singulares, sin la necesidad de ninguna otra premisa. Así, cuando el lexicógrafo hipotético ha logrado confeccionar un manual de traducción de un idioma desconocido, no ha hecho más que proyectar su ontología en aquel idioma, y ello precisamente a través del mecanismo acostumbrado de seleccionar un universo del discurso para las variables: "Ha decidido qué expresiones deberá considerar como referentes a objetos, y dentro de ciertos límites, a qué tipos de objetos se refieren. Ha debido decidir, aunque arbitrariamente, la manera de acomodar la concepción castellana de la identidad y la cuantificación en la versión nativa" (1958a, pp. 15-16). Ni qué decir tiene que ello conduce, también sin más, a la inescrutabilidad de la referencia; pues saber a qué se refiere una expresión no es, lo hemos visto más arriba, sino atribuir nosotros un campo a las variables del idioma del que esa expresión forma parte: "la arbitrariedad de lecr nucstras objetivaciones en la lengua nativa no refleja tanto la inescrutabilidad de la mente indígena como que no hay nada que escrutar" (1958a, p. 17).

Por último, incluso la indistinción analítico-sintético y el rechazo del reduccionimo observacional (los dos "dogmas del empirismo") pueden verse como nuevas consecuencias del compromiso ontológico. En primer lugar, porque partiendo de cierta estructura de variables de cuantificiación da lo mismo que los objetos que han de servir de valores sean concretos o abstractos (19.52a, p. 303), con lo que la referencia opera al margen de que cstemos hablando de objetos físicos o de entidades, por cjemplo, de la lógica o la matemática. Esto solo

sintético: "If there is no proper distinction between the analytic and the synthetic, then no basis at all remains for the contrast which Camap urges between analytical and empirical statements of existence. Ontological questions then end up on a par with questions of natural science" (ibid., p. 71). 
ya haría que los enunciados no fueran analíticos (puros) o sintéticos (empíricos) por referirse o no a lo observable desde el punto de vista de su verdad. Pero es que, en segundo lugar, puesto que es la estructura cuantificacional la que determina, en su conjunto, la referencia, a través de los predicados que son atribuidos a los "huecos" de las variables, entonces no tiene sentido tampoco hablar de enunciados analíticos o sintéticos de manera aislada, sino que habrá siempre que considerar un conjunto completo de ellos, es decir, un lenguaje, que es la unidad referencial mínima (por expresarlo de forma no quineana).

Consiguientemente el dogma reduccionista (la reducción de lo teórico a lo observacional) no se sostiene y su derrumbamiento nos lleva directamente a la última tesis que quería mencionar: el holismo (la tesis Duhem-Quine). En efccto: "nuestros enunciados acerca del mundo externo se somcten como cuerpo total al tribunal de la experiencia sensible, y no individualmente" (1951a, p. 75). Lo cual no es más que decir que aquello a lo que nos referimos cuando hablamos en términos observacionales está ya determinado por la globalidad de la estructura cuantificacional. De ahí que Quine haya insistido en la profunda conexión entre los dos "dogmas": "mientras se considere significante en general hablar de la confirmación o la invalidación de un enunciado, parece también significante hablar de un tipo límite de enunciados que resultan confirmados vacuamente, ipso facto, ocurra lo que ocurra; esos enunciados son analíticos" (ibid.). Eso hace que la separación entre una componente lingüística y otra factual, por lo que se rcfiere a un enunciado, sea algo insostenible y, por tanto, que haya que remontarse al lenguaje en su conjunto, lo quc implica todo un esquema conceptual a través de la correspondicnte ontología incrustada en el valor referencial de la estructura cuantificacional. Así, la raíz del compromiso ontológico nutre y afecta a toda la filosofía quineana, y elio incluso antes de que su obra básica, Palabra y objeto, fuese publicada en 1960. 
Para resumir la profunda unidad que he intentado dibujar en esta primera sección quisiera transcribir un texto de Blasco (1974a, p. 131), que me parece especialmente esclarecedor, una vez bien complementado:

los elementos referenciales del lenguaje son los pronombres, $\mathbf{o}$, hablando de un lenguaje formal, las variables. Con ello todos los nombres pasan a predicados de aquellos individuos que en tanto que valores de variables hagan verdaderos los enunciados. O dicho de otra manera, el campo de referencia de las variables son los individuos que satisfacen los predicados de dicha variable. Esto implica que los individuos han de reconocerse por los predicados, y el propio Quine dice en este sentido que "podemos afirmar que lo que aprendemos por ostensión, por confrontación directa, no son nunca nombres, sino sólo predicados". Los predicados no tienen posición referencial, pero son los que definen el campo de valores de las variables. En definitiva, pues, esto quiere decir, $[\ldots]$ que conocemos las cosas por sus características.

A través del lenguaje de Blasco, con un airc particularmente semántico (e incluso modclo-teórico), podemos inequívocamente intuir ya las consecuencias estructuralistas de la filosofía general de Quine, incluso antes de abordar su visión de la reducción matcmática. En efecto, da la sensación de que el pasaje está describiendo el hecho de que una estructura abstracta admita diversas interpretaciones, todas las cuales satisfarían sus axiomas. Lo que equivale a decir que lo que hace quc podamos hablar con sentido de ciertos objctos sea nada más que la cxistencia de una cstructura que los tome como valores o, lo que cs lo mismo, de un conjunto de postulados que los "definan implícitamente" - que determinen la clase de los modelos de la "tcoría" - a través de las variables de los postulados. Ello es como decir que las cosas son sólo conjuntos de relaciones o, más bien, que su "esencia" consiste sólo en un conjunto de propiedades (predicados) que cobran la apariencia de aplicación "a una cosa" a través de una estructura cuantificacional abstracta, que es lo único real. He señalado 
ya en otra parte ${ }^{4}$ que el artificio de la teoría de las descripciones de Russell ocasionó en su propia filosofía consecuencias holísticas de la mayor importancia, así que no creo que deba sorprendernos que la unidad profunda de la filosofía de Quine radique precisamente en ese punto.

Esa unidad subyacente es la que ahora quisiera utilizar como plataforma a partir de la cual hacer inteligible la teoría quineana de la reducción matemática, al tiempo que destacar sus problemas, lo que nos servirá, a su vez, de base para discutir la problemática ontológica de la reducción y otras cuestiones de la filosofía contemporánea de la matemática.

\section{Ontología y reducción matemática}

Palabra y objeto es la fuente básica pertinente ahora. De acuerdo con esa obra, el punto de partida de cualquier reducción puede sólo ser el punto de vista global del conjunto total de nuestro conocimiento, expresado y constituido a través de un lenguaje determinado: "No se verá qué objetos hemos afirmado hasta que los términos considerados se encuentren en un encaje adecuado con todo el aparato objetivador del lenguaje: artículos, pronombres, los giros de la identidad, la pluralidad y la predicación, o, en la notación canónica, la cuantificación" (1960a $\S 48$, p. 246). P.r tanto, si ha de juzgarse acerca de la aceptabilidad de cualquier reducción matemática, como es la de los números a coniuntos, ello podrá hacerse sólo en función de la eficacia global considerando el sistema como un todo. Así, optar por el nominalismo o el realismo depende del sistema global que queramos constituir: "Le razón para admitir números como objctos es precisamente su eficacia en la organización y la acomodación expedita de las ciencias. Y la razón para admitir clases es prácticamente la misma" (ibid.). Volvemos, así a la asimilación ontoló $\varepsilon^{i}$ ca de objetos concretos y abstractos que

4 Véanse mis 1989a, 1990b y 1991 a (cap. 5). 
señalábamos más arriba: "la distinción entre la existencia de un sentido de 'hay' para los objetos concretos y otro para los abstractos y la existencia de un solo sentido de 'hay' para unos y otros no tiene el menor sentido" (ibid., p. 251).

Podemos colegir ya un criterio de aceptabilidad para las reducciones, que naturalmente no es otro que el que el propio Russell descubrió en su propia teoría de las "construcciones lógicas" — de la cual las descripciones fueron sólo un ejemplo más, y no el primero- y aplicó sistemáticamente: serán válidas aquellas que cumplan con la función de las entidades por reducir (la cual depende del mantenimiento de la estructura general y del cumplimiento de las mismas "leyes"), al tiempo que redefinan los enunciados en los que aquéllas aparecían en términos de otros en los que tengan lugar las entidades reductoras. Ésa es exactamente la interpretación quineana del ejemplo de la eliminación de los infinitesimales por Weierstrass, que mostró "cómo pueden reconstruirse las sentencias del cálculo diferencial de tal modo que no tomen como valores de las variables más que números propiamente dichos, sin perjudicar al mismo tiempo la utilidad del cálculo" (1960a, § 51, p. 258). No obstante, y esto es importantísimo, las paráfrasis por medio de las cuales debe llevarse a cabo la reconstrucción "no pretenden alcanzar sinonimia" (ibid., p. 259), lo que remite al usual rechazo quineano del mito del significado y su sustitución por el "mito" de la referencia, el único compatible con su marco general de la estructura cuantificacional y el compromiso ontológico. ${ }^{5}$

5 Aquí Quine no ha sido, no obstante, muy claro, en lo tocante a la fundamentación de su filosofía global. Que yo sepa ha propuesto como alternativa a una búsqueda -inútil- de sinonimia, criterios tan metafóricos como la "máxima del análisis somero: no exponer más estructura lógica que la que parezca útil para la deducción o investigación en curso" (1960a, $\S 34$, p. 170). Pcro a la hora de abordar el problema general del valor de las reduccioncs en el marco del paso del lenguaje ordinario al científico ha introducido sólo reflexiones de sentido común: "Cada reducción que conseguimos en el seno de la variedad de construcciones constituyentes 
Ni qué decir tiene que tal criterio de reducción es, admitidamente, extraído del análisis de los nombres propios en términos de descripciones, a título de lección metodológica. He aquí el texto básico, que nos sirve para introducir una nueva particularidad del criterio total: las paráfrasis dcben facilitar el análisis veritativo que resultaba problemático aplicado a los enunciados en términos de las entidades por reducir (1960a $\S 38$, p. 191):

Hay un modo claro en el cual nuestro nuevo análisis de los nombres como términos generales se separa del uso ordinario, no ya de la corriente manera de clasificar ese uso cn categorías: nuestro nuevo análisis colma las lagunas verititativas. Pero ésta era precisamente la finalidad de ese nuevo análisis. El resultado sería sospechoso y condenable si la paráfrasis pretendiera sinonimia; pero no la pretende. Una paráfrasis en notación canónica es buena en la medida en que tiende a satisfacer necesidades para las cuales se deseó precisamente formular el texto original parafraseado luego.

Quine ha presentado determinada reconstrucción como paradigmática: la del par ordenado en términos conjuntistas, que le ha servido como ejemplo para abordar despućs la que a nosotros nos interesa más: la de los números a conjuntos. Veamos lo esencial de la primera.

Ante todo está la ú unca función (ley) que el par ordenado debe cumplir: dos pares ordenados son iguales cuando sus respectivos términos lo son. Cualquier reconstrucción debe conservar tal función, al tiempo que, como hemos visto, clarificar la noción original en el sentido de adecuarla mejor a cierto contexto teórico, como por ejemplo es aquí la de reducirla a un nuevo contexto ontológico: el de las clases (con ello

que se necesitan para construir las sentencias de la ciencia es una simplificación de la estructura del amplio esquema conceptual científico. Cada eliminación que consigan is de construcciones o nociones oscuras mediante paráfrasis con elementos más lúcidos será una clarificación del esquema conceptual de la ciencia" (ibid.). 
ya no sería necesaria una lógica de relaciones, frente a la de las clases, dado que las relaciones se pueden reducir a pares ordenados). De las diversas reducciones posibles la primera fue ofrecida por Wiener en 1914, en términos de clase unitaria y clase nula (ligeramente simplificada por Quinc):

$$
\langle x, y\rangle=\{\{x\},\{y, \Lambda\}\}
$$

Los comentarios de Quine son fundamentales para entender su postura general sobre la reducción (que es aquí asimilada al análisis y a la explicación), así que merece la pena citar con generosidad (1960a, $\S 53$, p. 267):

Esa construcción es paradigmática de lo que típicamente buscamos cuando, con espíritu filosófico, ofrecemos un "análisis" o una "explicación" de alguna "idea" o expresión hasta entonces formulada inadecuadamente. No pretendemos sinonimia. No pretendemos aclarar ni explicitar lo que tienen inconscientemente en la cabeza los que usan la expresión sin aclarar. No pretendemos exponer significaciones ocultas, contra lo que sugieren las palabras "análisis" y "explicación": lo que hacemos es llenar lagunas, cubrir deficiencias. Establecemos las funciones de la expresión oscura que la hacen merecedora de esfuerzos, y entonces establecemos un sucedáneo de ella, claro y formulado con los términos preferibles, el cual satisface aquellas funciones. Aparte de esas condiciones de concordancia parcial, dictadas por nuestros intereses y fines, todos los demás rasgos del explicans caen bajo el rótulo del "esigual" [don't care], son "esiguales". Y, situados bajo ese rótulo, podemos permitir que el explicans tenga cualesquiera connotaciones nuevas, jamás asociadas con el explicandum.

Sin embargo, son posibles muchas otras reducciones, como la de Kuratowski, e incluso otras que no respeten ni siquiera el contexto conjuntista. Además, puesto que cada una de ellas es incompatible con las demás, $\mathrm{cn}$ el sentido (no especificado por Quine) de que diversos en unciados que contengan unas u otras pueden tener valores de verdad diferentes, surge inevitable- 
mente la pregunta de cuál de ellas es "la buena". La respuesta de Quine es directa: todas lo son, pues todas satisfacen la única función que se exige del par ordenado (ibid., p. 268).

La generalización es inmediata: explicar es eliminar, en el sentido pragmático de ambas expresiones (1960a, p. 269):

Empezamos con una expresión o forma de expresión que resulta turbadora o molesta. Se comporta en parte como un término, pero no suficientemente, o bien es vaga hasta la incomodidad, o produce tensiones en una teoría, o suscita confusiones. Pero, por otra parte, sirve a determinados fines que no dchen abandonarse. Entonces descubrimos un modo de conseguir los mismos fines a través de otras vías, utilizando formas de expresión menos turbadoras. Con eso se resuelven las anteriores perplejidades.

Es más, tales perplejidades tienen un sentido puramente lingüístico, originado en las connotaciones innecesarias de la expresión originaria por eliminar, o bien en ciertos usos igualmente prescindibles. Y aquí es donde Quine se separa de Russell, por cuanto el viejo maestro había estado siempre convencido de que, a pesar del matiz convencional de las construcciones, éstas han de poseer, si son aceptables, un valor profundo en el sentido de que a través de ellas ampliamos nuestro conocimiento, y no meramente adoptamos una táctica artificiosa y útil, es decir resolvemos un problema auténtico desde el punto de vista ontológico: descubrimos lo que realmente era una entidad. ${ }^{6}$ En cambio, para Quine no hay tal cosa; es cierto que había un problema filosófico de partida, pero su naturaleza era puramente lingüística, en el sentido wittgensteiniano del término. Por tanto de lo que se trata es de disolverlo, tanto en el raso del par ordenado como en el de ejemplos similares: "En 1: dos los casos se disuclven los problemas en el sentido de que se muestra que son puramente verbales, y puramente verbales, a su vez, en el elevante sentido de surgir puramente de

'Véase mi 1989h. 
usos lingüísticos que pueden evitarse en favor de otros que no producen tales problemas" (1960a, p. 269).

La conexión con Wittgenstein no es casual; existe un profundo nexo entre el compromiso ontológico y la teoría de la disolución de los problemas a través del estudio de los usos lingüísticos, a la par que una importante diferencia. Quine ironiza con el hecho de que sean precisamente los partidarios de Wittgenstein los que rechacen su tipo de explicación; pero lo hace alegando que la mejor manera de mostrar que un problema es puramente verbal es haciendo ver "cómo pueden eludirse las partes problemáticas del uso ordinario" (ibid., p. 270). Con ello presupone que su modelo de reducción es wittgensteiniano al apoyarse en algo muy parecido al significado como uso (en el sentido referencial del término).

En efecto, son los usos similares de las diversas expresiones lo que nos permite sustituir unas por otras, dejando de lado connotaciones innecesarias. Ése sería el nexo que señalaba más arriba, que se hace posible precisamente gracias a la forma en que Quine entiende el lenguaje: como una especie de estructura global en la que unas partes funcionan (existen) por referencia al resto. Pero la diferencia es grande: para Wittgenstein el uso no puede crearse a voluntad, así que el cumplir una ley (la del par ordenado, por ejemplo) no puede tomarse como sinónimo del "uso" en el sentido técnicamente relevante, para cuya determinación cuenta sólo el uso efectivamente observado.

Sin embargo para Quine sí que puede crearse el uso; basta con ir acostumbrándose a los nuevos términos, introducidos por las expresiones escogidas para sustituir a aquellas que han de eliminarse: "Si había en medio una cuestión referente a objetos y se consigue el paralelismo parcial del que hablamos, los objetos correspondientes al nuevo esquema irán viéndose como los viejos objetos misteriosos liberados de su antiguo misterio" (1960a, p. 270). En todo caso lo que no ofrece ninguna duda es que, como decía más arriba, el nexo con Wittgenstein se 
produce precisamente gracias al compromiso ontológico; no de otra forma ha de entenderse la referencia a los objetos del pasaje citado. Así, los “objetos" anteriores son sustituidos por los nuevos, pero ello s6́lo en el sentido de que un esquema - y por tanto un modelo de variables cuantificacionales- es cambiado por otro. Desgraciadamente ello no se ve tan claro cuando Quine trata de aplicar estas ideas a la reducción matemática por excelencia: la de los números a conjuntos.

En 1960a Quine sitúa la pregunta por la esencia de los números en el mismo plano que la correspondiente del par ordenado, con sólo sustituir a Wiener por Frege y a Kuratowski por von Neumann. Así, tanto Frege como von Neumann, o Zermelo, identificaron los números particulares con ciertas clases (o conjuntos) de forma que la secuencia general resultase reconstruida y fuese susceptible de cumplir las mismas funciones que la original. El problema de las distintas propiedades de los constructos respecto a las entidades originarias se resuelve atendiendo a la característica básica común: ambos son progresiones (series infinitas cuyos miembros tienen todos una serie finita de precursores), y eso es todo lo que debemos exigir de cualquier explicación aceptable del número (1960a, § 54, p. 271). El problema ulterior, planteado por Russell, de que cualquier constructo para los números deberá tener la misma capacidad de cara a la; aplicaciones (contar y medir), se soluciona aludiendo a lá capacidad de cualquier progresión de ser puesta en correspondencia biunívoca con otra. Así, decir "hay $n$ objetos $x$ tales que $F x$ " es decir "los números menores que $x$ admitcn una correlación con los objetos $x$ tales que $F x$ ", y ello exige sólo desarrollar una teoría de relaciones capaz de ofrecer una noción clara de correlación, pero "no exige nada especial acerca de los números, exeepto que éstos formen una progresión" (ibid.).

Finalmente, el prol lema de la intuitividad debe plantearse atcndicndo a la característica principal de cada reconstrucción, de forma que ella sirva de apoyo intuitivo a cada alter- 
nativa. Así, en Frege se defenderá que el número es de forma natural una propiedad de clases y en von Neumann se atenderá más bien a su utilidad básica, la de contar, para resaltar la identificación de un número $n$ con la clase de los $n$ primeros números de la progresión. Desgraciadamente Quine elude así el hecho de que para Frege y Russell uno de los motivos principales de la sustitución era la logicización en sí misma, pues sólo de esa forma veían posible una rigorización de la serie numérica desde el punto de vista de la verdad de los enunciados numéricos, es decir, atendiendo a la capacidad de las verdades aritméticas de ser deducidas de verdades lógicas, cosa que no sucedía para nada en las versiones de von Neumann, Zermelo, o cualquier otra de enfoque conjuntista. Así, el problema de la intuitividad está, creo yo, mal planteado, pues olvida el estrecho nexo entre intuición, verdad y evidencia (las leyes lógicas se suponía que eran evidentes por sí mismas).

Además, otra diferencia básica entre el conjuntismo y FregeRussell es que en el segundo caso la progresión se construye con carácter secundario, en el sentido de que primero es el número cardinal y luego el ordinal, como lo demuestra el hecho de que el primero pueda definirse atendiendo a menos propiedades y pueda, además, introducirse sin distinción explícita entre finito e infinito, siguiendo la idea básica de Cantor (y contra Dedekind, partidario de la visión ordinal). Esto hace que Quine no se plantee para nada la postura de los axiomas de Peano ni su posible interpretación multívoca, visto que para él la progresión, es decir, la mera estructura ordinal, es lo primario, lo que equivale a decir que el número es esencialmente lo que ocupa cierta posición en una serie, y es evidente que ello requiere alguna justificación. Así, tampoco el problema de las interpretaciones no estándar de los axiomas de Peano (célebre ya desde Skolem y Henkin) recibe el menor tratamiento, a pesar de que tal problema remite directamente a la cuestión de que junto a unas condiciones suficientes para la reducción, cabe hablar también de unas condiciones necesarias. 
La limitación de su planteamiento lleva a Quine a una carencia aún más importante: olvida que el estatus de la reducción, o explicación, es muy distinto en la versión conjuntista que en la de Frege-Russell. Así, escribe que las tres progresiones de Frege, von Neumann y Zermelo están presentes en el mismo universo de valores para las variables (presumiblemente el de los números), por lo que (1960a, p. 272):

Las tres son adecuadas como explicación del número natural, en el sentido de que no es necesario, disponiendo de cualquiera de ellas, añadir a nuestro universo del discurso los números naturales en ninguna función propia. Cada una de las tres progresiones, o cualquier otra, hará el trabajo de los números naturales, y cada una de ellas resulta además dotada para tarcas que no pueden cumplir las demás. Así se nos impone el hecho, como en el caso de los pares ordenados, de que la explicación es eliminación.

Pero ni para Frege ni para Russell (al menos el primer Russell) los números quedaban eliminados al ser reducidos a clases de clases. Para ellos la realidad de los números era tan firme como la de los objetos físicos, en el sentido platónico de que las entidades aritméticas, como las de la geografía, se descubren y no se crean mediante su construcción. Así, si es necesario reconstruirlas en términos lógicos ello se debe, como decía más arriba, a la necesidad de asegurar su estatus lógico y justificar la verdad de los enunciados correspondientes. Pcro ello no significa en ningún caso que se trate sólo de cumplir ciertas funciones: los númcros son objetos independientes de nosotros y todas nuestras rcconstrucciones; no son reducibles a las leyes que los rigen, por lo que ninguna otra entidad que cumpla tales leyes puede aspirar a sustituirlas.

En 1963a Quine mantiene idéntico planteamiento, aunque añade algo importante, que será desarrollado con posterioridad en términos de preservación de estructura: las diferentes progresiones sustituyen válidamente a los números (cumplen sus mismas funciones) porque, en general, suponen reducción sólo 
en el sentido de modelización. Así, los números son conjuntos sólo en el sentido de que las expresiones aritméticas pueden ser reinterpretadas de forma conjuntista, lo que preserva la verdad de los enunciados correspondientes (1963a, p. 135): ${ }^{7}$

Hemos aportado un modelo para la aritmética en la teoría de conjuntos cuando hemos aportado una manera de interpretar las notaciones aritméticas en términos conjuntistas de forma que las verdades de la aritmética pasen a ser verdades de la teoría de conjuntos. Entonces, ¿́qué es lo que se requiere, además de esa simulación formal, al reducir realmente los números a la teoría de conjuntos? Similarmente, hay también una cuestión de aplicación de los números; así, en el caso de los números naturales, la medida de una clase. Pero habíamos notado [...] que esto no constituía ningún requerimiento adicional para los números naturales; cualquier versión de los números naturales serviría para la medida de una clase si cumpliese las leyes formales [...] El modelado, de nuevo, se muestra como equivalente a la reducción porque todas las características relevantes para la aplicación pasan al seno del modelo.

Ello no supone, sin embargo, ningún avance en los problemas que he señalado más arriba. La cuestión de la intuitividad (que depende, claro está, del tema del lenguaje ordinario) queda pendiente, así como el problema de la reducción, en el sentido eliminativo del término, junto a los temas de la prioridad cardinal-ordinal y de los modelos no estándar.

\section{Pilagorización y reducción}

Al año siguiente Quine dedicó un importante artículo al tema: 1964a, que scrá ya la versión definitiva de su postura, a la que sólo se han añadido posteriormente cicrtos detalles

7 Aunque la preservación de la verdad de ciertos enunciados de un morlelo reductivo no tiene por qué conservarse en otro. La incompatibilidad es más profunda de lo que parece (Benacerraf en 1965a señaló esto con claridad). Io que se preserva es la verdad de los enunciados de la aritmética clásica de números en los diversos morelos propuestos. 
secundarios. Yo veo dos novedades importantes en esta nueva entrega. La primera es una cierta clarificación del concepto de reducción ontológica, consistente en señalar, por primera vez, el hecho de que ciertas reducciones pretenden sólo sustituir ciertas entidades por construcciones que cumplan sus funciones esenciales, mientras otras pretenden, además, eliminar las entidades originarias, mostrando, así, su dispensabilidad. Quine ofrece un ejemplo extraído de Carnap en el que cierto tipo de números es eliminado en términos de ciertos otros y concluye: "Las clases de Frege y las de von Neumann simulan el comportamiento de los números naturales hasta el punto de que resulta cómodo llamarlas números naturales, en lugar de decir que hemos logrado prescindir de los números naturales como Carnap prescindió de los números impuros" (1964a, p. 200).

La distinción parece banal, pero es dañina para la tesis anterior de Quine de que toda reducción presupone la eliminación de lo reconstruido. Cuando él mantenía semejante postura es obvio que estaba pensando en su típico esquema de la reconstrucción como paráfrasis (véase más arriba), donde lo único que contaba era la sustitución dentro del enfoque del compromiso ontológico, es decir, partiendo de la base de que ser es sólo ser dentro de una estructura cuantificacional dada. Como Quine extrajo su teoría general del modelo de la teoría de las descripciones extendido a todos lo objetos abstractos y a todos los nombres propios, carecía de sentido para él distinguir entre dos tipos de reducción de unos objetos a otros fuera del marco estricto de la relatividad ontológica, que pasa meramente por sustituir una teoría por otra. Por tanto no podía, en su sistema, decirse que unas entidades son eliminadas (por ejemplo ciertas descripciones "sin referencia", como el famoso actual rey de Francia de Russell), mientras que otras son simplemente parafraseadas. Toda reducción debía ser eliminación. Ahora, sin embargo, sin desdecirse explícitamente de su planteamiento anterior, Quine al menos admite que hay reducciones que eli- 
minan y otras que no lo hacen necesariamente, $o$ al menos que no se introdujeron con objeto de eliminar nada.

Lo que Quine señala ahora es que, por tanto, lo que llama coextensividad no es todo ni lo único que se busca en toda reducción. Si la coextensividad fuese lo único interesante sería cierto que toda reducción sería eliminación, pero como hay reducciones que eliminan realmente lo reconstruido, en el sentido de que muestran claramente su dispensabilidad (o, como diría Russell, su falta de referencia), mientras que otras no lo hacen, pudiendo, por tanto, coexistir —a título alternativocon las entidades originarias, entonces hemos de concluir que reducción y eliminación no son, a su vez, nociones coextensivas. Pcro esto no le sirve a Quine para modificar, en apariencia, su planteamiento general anterior, salvo en el scntido de añadir explícitamente que las reducciones de los números a conjuntos valen porque preservan la estructura (1964a, p. 200):

Allí donde la reducción es parcialmente ontológica, vemos que la coextensividad no es la cuestión. ¿Qué lo es entonces? Considérense de nuevo los modelos de Frege y von Neumann de construir el número nalural, así como un tercero y bien conocido: el de Zermelo. ¿Por qué son todos ellos válidos? ¿Qué tienen en común? Cada uno de ellos es un modelo que preserva la estructura de los números naturales. Cada uno preserva la aritmética, y esto es suficiente.

Sin embargo, Quine está pensando ya en otra cosa, y ésa es la segunda novcdad básica mencionada más arriba; está pensando cn que si la coextensividad no es exacamente lo digno de destacarse, pucsto que caben dos sentidos distintos de eliminación de lo reconstruido, entonces hay que añadir alguna condición ultcrior que distinga una climinación de la otra. Lo curioso es que se sirva de otro de los problemas que mencionábamos más arriba como pendientes para hacerlo: el problema de la no-categoricidad tal como se infiere del teorema de löwenheim-Skolem. 
En efecto, si describimos las distintas (e incompatibles) reducciones matemáticas de los naturales a conjuntos (o de los reales a racionales, $u$ otras similares) en términos de preservación de estructura, es decir, en términos modelísticos, entonces hemos de admitir también, por el susodicho teorema, que cualquier modelo conjuntista al que reduzcamos los números tiene, a su vez, un modelo en el universo de los números naturales, pues lo que el teorema afirma es precisamente que cualquier teoría que admita una interpretación verdadcra admite un modelo tal. El problema queda, así, servido (1964a, p. 210):

Existe aquí otra interesante cara de la moneda. Nuestros primeros ejemplos de reducción ontológica fueron las reducciones de Frege y von Neumann de los números naturalcs a la teoría de conjuntos. Éstos y otros ejemplos reforzaron la idea de que lo que importa de tales reducciones es el descubrimiento de un modelo. Y así terminamos diciendo, a la vista del teorema de LöwenheimSkolem, que las teorías acerca de los objetos de cualquier tipo pueden, si son verdaderas, reducirse a teorías de números naturales. En lugar de reducir el discurso sobre números al discurso sobre conjuntos, podemos reducir el de conjuntos - y de todo lo demás - al de números naturales. Y hay aquí un beneficio evidente, puesto que los números naturales son relativamente claros y $[\ldots]$ económicos.

La conexión con el tema de la eliminación es obvia: si fuese cierto que lo único que importa es la preservación de la estructura, como Quine concluyó de las típicas reducciones conjuntistas, entonces deberíamos afirmar lo mismo ahora, admitiendo la sorprendente conclusión del célebre teorema según la cual cualquier teoría es reducible a la de los números naturales. En palabras de Quine (ibid., pp. 201-202):

Pero ¿es cierto que lo único que importa es un modelo? Cualquier teoría interpretable pucde, a la vista del tcorema de Löwenhcim-Skolem, ser modelada en los númcros naturales, sí; pero inos autoriza esto a decir que de esta forma la hacemos 
de una vez por todas reducible a ese dominio, en el sentido de que nos estuviera permitido en adelante repudiar los viejos objetos para cualquier propósito y reconocer sólo los nuevos, los números naturales?

Es pues obvio que la vieja teoría de la reducción quineana requiere algún cambio, a riesgo de llevar una y otra vez a la misma conclusión, aparentemente viciosa, y es obvio que ese cambio ha de afectar precisamente a la vieja identificación entre reducción y eliminación, en el sentido de romperla y admitir varios tipos de eliminación (como defendió ya Russell). Veamos la modificación y comprobemos si las exigcncias del célebre teorema sirven, de paso, para resolver los anteriores problemas pendientes.

No puedo aquí entrar en detalles, pero lo esencial del cambio me parece que radica en lo siguiente. Para Quine, la única forma de evitar la consecuencia de que, por el teorema de Löwenheim-Skolem, toda reducción ontológica (dentro de las condiciones estándar) pase a ser meramente una reducción a los números naturales, consiste en exigir como condición adicional la introducción de una función "sustitutiva" (proxy) que preserve las propiedades - los predicados_- de las entidades originarias - vía mantenimiento de los valores de vcrdad de los enunciados relevantes - tras su proyección en un nuevo modelo. La idea intuitiva es que la función sustitutiva asigne una de las nuevas entidades del modelo a cada una de las entidades originarias por reducir, con lo cual la "trivializacion" de la anterior reducción podría evitarse. En palabras de Quinc (1964a, p. 205):

El esquemá estándar de la reducción de una teoría $\theta$ a otra $\theta^{\prime}$ puede ahora establecerse como sigue. Especificamos una función, no necesariamentc en la notación de $\theta$ o de $\theta^{\prime}$, que admita como argumentos todos los objetos del universo de $\theta$ y tome valores en el universo de $\theta^{\prime}$. Ésta scrá la función sustitutiva. Luego a cada predicado primiţivo $n$-ádico de $\theta$, a cada $n$, le asociamos de 
manera efectiva un enunciado abierto de $\theta^{\prime}$ de $n$ variables libres, de tal manera que el predicado sea satisfecho por un $n$-tuplo de argumentos de la función sustitutiva cuando y sólo cuando el enunciado abierto sea satisfecho por el correspondiente $n$-tuplo de valores.

No cabe duda de que con semejante condición la amenaza procedente del teorema de Löwenheim-Skolem no tiene ya lugar. Para una reducción realmente ontológica, y no un mero "modelizado", de una teoría a los números naturales es necesario ahora que se determine una función sustitutiva que asigne efectivamente números a todos los objetos de la teoría originaria y proyecte sus predicados en sentencias abiertas del modelo numérico, con objeto de preservar los valores de verdad de las sentencias cerradas. Pero el argumento basado en el teorema de Löwenheim-Skolem no determina tal función: "No resulta determinado qué números han de equivaler a los respectivos objetos de $\theta$. De ahí que ello no dé la medida de nuestro estándar de reducción ontológica" (1964a, p. 206).

Sin embargo, y como era previsible, se crea un problema nuevo. Si hemos de distinguir entre reducción ontológica y mero modelado es al precio de introducir una función entre las entidades de ambas teorías, lo cual presupone el considerarlas como objetos, aparentemente con igualdad de estatus ontológico. Pero con ello la vieja tesis de que la reducción (o explicación) equivale a eliminación, que tuvo ya que ser corregida hasta distinguir entre eliminaciones "tácticas" y eliminaciones reales, tiene ahora que ser desechada completamente. Si ambos tipos de entidades tienen el mismo estatus ontológico, entonces no podemos decir que los primeros han quedado eliminados por - o reducidos en términos de - los segundos. Así, aunque sin duda la reducción fregeana - y similares - cumple la condición adicional (hay una función que, aplicada a los números, nos da como valor la clase dc clases correspondiente), ello supone hacer de los números entidades "auténticas", con lo que 
la razón principal de la reducción —que era, desde el punto de vista de Quine, el lograr las mismas funciones con sólo admitir entidades (las clases o conjuntos) menos problemáticas que los números - pierde su sentido.

Por tanto, el precio que pagamos para evitar que cualquier reducción conjuntista suponga, por el teorema de LöwenheimSkolem, una reducción a los números naturales, se continúa pagando a manos de su función sustitutiva, que nos impide librarnos de los números de todas formas. Esto ha sido reconocido explícitamente por Quine, que introduce, de paso, otra consecuencia de la maniobra: "Mi formulación pertenece, por su naturaleza, a una teoría inclusiva que admita los objetos de $\theta$, aún por reducir, y los objetos de $\theta^{\prime}$ en pie de igualdad" (1964a, p. 206). La consecuencia es, naturalmente, que se exige también una especie de nueva teoría "inclusiva" desde donde podamos considerar ese nuevo estatus ontológico al mismo nivel para ambos tipos de objetos. Parece cierto que sólo desde esa teoría adicional podría lograr la maniobra, o, dicho en otras palabras, formular explícitamente la función sustitutiva, pero Quine nos deja aquí sin saber nada más con respecto al estatus de la nueva teoría.

Afortunadamente un célebre artículo posterior, "La relatividad ontológica" (1969a), da el paso definitivo: identificar la teoría adicional nada menos que con la "teoría de fondo" requerida para poder reducir una teoría a otra, con lo que podemos comprobar que la versión final de la tesis de la relatividad ontológica depende precisamente de la evolución de los problemas de la reducción matemática. Aparentemente la versión quineana de la reducción de los números a conjuntos de 1969a es la misma (p. 62-63):

En última instancia, ¿qué es un número natural? Existen la versión de Fregc, la dc Zermelo, la de von Ncumann $\mathrm{c}$ incontables alternativas ulteriores, todas cllas mutuamente incompatibles e igualmente correctas. Io que estamos haciendo en cualquiera de estas explicaciones de los números naturales es idear modelos 
de la teoría de conjuntos para satisfacer leyes que los números naturales en un sentido no explicado han sido destinados a satisfacer.

Sin embargo, ya una primera precaución referente a los modelos no estándar descubiertos por Skolem muestra que Quine se toma cada vez más en serio los problemas de la reducción ontológica en matemática. En las anteriores discusiones nunca habíamos visto aparecer este importante tema, y la acostumbrada alusión a Russell se liquidaba siempre diciendo que el viejo maestro se equivocaba cuando requería algo más que un simple modelo que satisficiese los axiomas de Peano (aunque Quine no suele referirse a tales axiomas en semejante contexto). Es obvio que cuando Russell manifestaba tal oposición lo hacía empujado por su clásica animadversión contra la "definición implícita por postulados", aunque Skolem se encargó después de demostrar que por debajo de aquella repulsión instintiva había algo más profundo. En consecuencia, Quine rectifica un tanto su presentación habitual. Así, aunque continúa defendiendo afirmaciones como "Los números [...] se conocen solamente por sus leyes", "Siempre, si hay estructura, las aplicaciones encajarán", o "las leyes aritméticas agotan la naturaleza de los números" (1969a, p. 64 s.), inmediatamente las corrige negando, con $R$ ussell, que los números sean simplemente "cualcsquiera cısas que satisfagan la aritmética", pues "distintos modelos de objetos dan lugar a distintos modelos de aritmética" (ibid., p. 65).

Así, la acostumbrada tesis de que cualquier progresión puede servir ha de modificarse: no podemos identificar unas progresiones con otras (por ejemplo la de los pares con la de los impars). Esto lleva el relativismo un paso más lejos (1969a, p. 65):

La cuestión sutil es que cualquier progresión servirá como una versión del número en la medida y sólo en la medida en que nosotros persistamos en una y la misma progresión. Aritmética es, 
en este sentido todo lo que es numerable: no hay, absolutamente hablando, lo que los números son; hay solamente aritmética.

No obstante, el nuevo grado de relativismo persistentemente se niega a presentarse a través de un tratamiento quizá más natural mediante los axiomas de Peano, en lugar de un vago lenguaje de las "progresiones", sobre todo puesto que tales axiomas las rigen a todas, lo que llevó a Peano a decir precisamente que el número es lo que podemos abstraer en común de todas las interpretaciones de sus axiomas. En todo caso la fuerte negación de cualquier esencia de los números está, en este estadio, necesitada de una nueva justificación relativista: es la función del nexo entre las consecuencias del teorema de Löwenheim-Skolem, la función sustitutiva necesaria para negar sus implicaciones y las novedades relativas a una nueva "teoría de fondo".

En efecto, el susodicho teorema establece una reducción de cualquier teoría a una ontología enumerable, lo que nos permite ver sus objetos como números naturales. Como anteriormente, Quine introduce la necesidad de una función sustitutiva que - como la numeración gödeliana - aplique un universo a una parte o a la totalidad de otro $(1969 \mathrm{a}, \mathrm{pp} .77,82)$. Esto conduce, también como de costumbre, al rechazo del pitagorismo a que llevaría aceptar la anterior reducción universal al mundo de los naturales: "Yo no veo incluso en la prueba del teorema fuerte de Löwenheim-Skolem ninguna razón para suponer que pueda formularse en parte alguna una función vicaria que aplique una ontología no enumerable, por ejemplo los números reales, a una enumerable" (ibid., p. 82-83).

Pero esto, aunque permite a Quine rechazar tan desagradable consecuencia, tiene — como vimos - el efecto de exigir de las entidades de la teoría por reducir un carácter inequívoco de "objetos", puesto que la función sustitutiva debe correlacionar los predicados de ambas teorías, y tales predicados lo son en la medida en que son verdaderos de los respectivos objetos. La 
consecuencia es la "teoría de fondo" para albergar la mencionada función y - de paso- la profundización del relativismo (ibid., p. 79):

Nuestra dependencia de una teoría de fondo se hace especialmente evidente cuando reducimos nuestro universo $U$ a otro $V$ apelando a una función vicaria. Ya que sólo en una teoría con un universo inclusivo, que abarque $U$ y $V$, puede tener sentido una función vicaria. La función aplica $U$ a $V$, en consecuencia, necesita tanto todos los viejos objetos de $U$ como sus nuevos vicarios en $V$.

¿Hasta qué punto hay que conceder, pues, un estatus ontológico pleno a los objeto por reducir? El asunto es peliagudo, sobre todo porque en algunos casos reducimos ciertos objetos a otros precisamente porque dudamos de tal estatus, $o$ incluso lo negamos abiertamente (descripciones sin referencia, infinitesimales después de Weierstrass, etc.). Para el caso de que la teoría de fondo coincida con la teoría por reducir, Quine lo formula en toda su desnudez, con su maestría habitual: "no podemos declarar nuestras nuevas economías ontológicas sin recurrir a la vieja ontología antieconómica" (1969a, p. 80). Pero el callejón sin salida no se admite: es cierto, nos dice, que los viejos objetos parecen existir, por cuanto necesitamos correlacionarlos con los ruevos, pero su estatus es meramente circunstancial y depen le sólo de la estructura de la argumentación (ibid., p. 80):

no hay más razón para preocuparse por esto que la que hay en la reductio ad absurdum, en la que suponemos una falsedad con el fin de probar que es falsa. Si lo que queremos mostrar es que el universo $U$ es excesivo y que sólo una parte existe o necesita existir, entonces estamos en nuestro pleno derecho de suponer todo $U$ para el argumento en cuestión. Mostramos así que si todo $U$ fuera necesario, ntonces no sería necesario todo $U$; y por tanto, nuestra reducción ontológica está marcada por la reductio ad absurdum. 
Sin embargo, es obvio que de esta forma se pierde una de las razones más fuertes de toda reducción ontológica. Como Russell mostró con su teoría de los símbolos incompletos, este tipo de reducciones tiene por objeto, no sólo mostrar quc podemos sustituir nuestras entidades problemáticas por otras más seguras que cumplan las funciones de las primeras, sino que podemos mostrar que al prescindir de ellas lo hacemos por medio de un nuevo lenguaje donde aparece con toda claridad que los objetos por rechazar no eran tales. Así, cuando Quine insiste en que los números no son nada, debe, sin embargo, pechar con la consecuencia de tener que admitirlos de todas formas, aunque sea de una forma vicaria, quizá en un sentido parecido al de Meinong cuando insistía en que "el cuadrado redondo" subsiste aunque no exista, micntras que la teoría de las descripciones russelliana lo reducía a la nada mostrando su carácter meramentc aparente.

Sólo ahora aparece la relatividad ontológica quineana en toda su fuerza, al tiempo que la inescrutabilidad de la rcferencia cobra nueva luz (1969a, p. 69):

Carece de sentido preguntar si, en general, nuestros términos "conejo", "parte de conejo", "número", etc., realmente se refieren respectivamente a conejos, partes de conejo, números, etc., y no a algunas denotaciones ingeniosamente permutadas. Carece de sentido preguntar esto en términos absolutos; podemos preguntar esto con sentido sólo relativamente a algún lenguaje de fondo [...] Cuestionarse la refereneia de una manera absoluta sería como preguntar por la posición absoluta, o la velocidad absoluta, en lugar de la posición o velocidad relativas a un sistema de referencia dado.

Naturalmente la nueva relatividad ontológica, que es mucho más fuerte que la anterior, tiene una consecuencia difícil de manejar, que inevitablemente recuerda la paradoja de Bradley sobre las relaciones. De la misma manera que para el viejo idealista todo intento de clarificar el estatus de la relación entre dos términos conduce a la conversión de tal relación en un 
nuevo término y reclama, por tanto, nuevas relaciones con los anteriores, en un regreso infinito, así parece suceder ahora con el lenguaje de fondo quineano. De nuevo nucstro autor diagnostica la situación con toda claridad: "Si las cuestiones de la referencia del tipo que estamos considerando tienen sentido sólo relativamente a un lenguaje de fondo, entonces evidentemente las cuestiones de la referencia del lenguaje de fondo tienen sentido a su vez sólo relativamente a un ulterior lenguaje de fondo" (1969a, p. 70). La solución es ya bradleyana sin ambages. Veámosla para terminar esta sección.

Decir si hay o no regreso infinito, al igual que sucede con la velocidad o la posición en una cadena de sistemas de referencia, puede responderse atribuyendo convencionalmente un punto dc partida "absoluto", que sería lo ostensivo en física como sustrato último y nuestro lenguaje ordinario como lenguaje de fondo último. Pero si queremos saber más y no limitarnos a algo tan prosaico como la práctica, Quine ofrece entonces el relativismo más profundo. Así como en física no hay más que relaciones de unos sistemas de coordenadas con otros $y$, por extensión de unas cosas con otras, sin que podamos hablar de cosas "en sî" absolutamentc, lo propio sucede con el lenguaje y los objetos de las teorías: sólo una "teoría relacional" sobre lo que son tales objetos buede servir: "La tesis relativista a la que hemos llegado [...] es ésta: no tiene sentido decir cuáles son los objetos de una teoría fuera de la cuestión de cómo intcrpretar o rcintcrpreiar esta teoría en otra" (1969a, p. 71).

Naturalmente no se trata de una "solución" al problema del lenguajc de fondo. Sc trata sólo de admitir que el problema no ticne mís solución que llevar el relativismo hasta sus últimas conseruencias: las cosas no son más que un conjunto de relaciones. Sin lugar a dudas el ciclo sc cicrra aquí, pues decir esto no es sino decir nomo insistíamos en la sccción anterior, que los nombres propios no son sino descripciones disfrazadas (que tambićn era una de las tesis básicas de Bradley), o que ser 
es ser el valor de una variable, o que, puesto que disponemos sólo de estructuras, un objeto no es sino una "posición" en una de ellas. Sólo ahora está Quine en disposición de superar el planteamiento carnapiano de cuestiones internas y externas: no hay posibilidad alguna siquiera de plantear la externalidad de una cuestión. Cuando pensamos en cuestiones externas inevitablemente lo hacemos en términos de un universo más amplio que rebase una teoría particular; ahora está claro que lo que hace que las cuestiones ontologicas carezcan de sentido cuando están tomadas absolutamente no es la universalidad, sino la circularidad" (1969a, p. 74).

Es este regusto bradleyano el que reconocemos una vez más en el recurso del lenguaje de fondo, y en el hecho de que la relatividad de que nos habla Quine es, como él mismo ha dicho, "doblemente relativa" (ibid., p. 76). En efecto: "la propia relativización tiene dos componentes: relatividad de la elección de la teoría de fondo y relatividad a la elección de cómo traducir la teoría objeto de la teoría de fondo" (1969a, p. 90); o, dicho en términos de la traducción radical: lenguaje de fondo y manual de traducción. Pero también la conexión implícita con el tema de los niveles del lenguaje, las paradojas y lo trascendental de todo intento de superación del relativismo ha sido señalado por Quine (ibid.):

La regresión en la ontología es reminiscente de la regresión ya familiar en la semántica de la verdad y nociones parejas — satisfacción, nombrar. Sabemos, a partir de los trabajos de Tarski, cómo, en este sentido, la semántica de una teoría reclama regularmente una teoría de algún modo más inclusiva. Esta semejanza quizá no debería sorprendernos, ya que tanto la ontología como la satisfacción son cuestiones de referencia. En su evasividad, de todos modos —en su vaciedad una y otra vez excepto en relación con un fondo más amplio-, ambas, verdad y ontología, puede decirse, en un sentido repentinamente claro e incluso tolerante, que pertenecen a la metafísica trascendental. 


\section{Reducción, explicación y eliminación}

En la sección anterior he ido formulando ya ciertas observaciones críticas a la postura de Quine, especialmente en lo que concierne a los problemas que me parecía que quedaban pendientes. Las más importantes han sido: el problema de si las nuevas construcciones amplían, como en Russell, nuestro conocimiento; la dificultad concerniente al uso ordinario de las expresiones; la ausencia de toda discusión refcrente a la prioridad de los cardinales o los ordinales, en el marco del intento de Frege-Russell, mucho más amplio que el de von Neumann y similares; el problema general de cualquier identificación entre reducción y eliminación; y la dificultad de la subsistencia de los objetos una vez reducidos, ahora en el marco del relativismo bradleyano de las cosas y las relaciones. En esta sección, y dando ya por supuestas tales críticas, repasaré otras que aparecen en los trabajos que tratan el tema y que me parecen especialmente útiles para profundizar las primeras y penetrar en los presupuestos quineanos.

Como señalé más arriba, Quine no suele hablar de los axiomas de Peano como estructura de todos los sistemas que forman una progresión. Pero uno de los axiomas, el que define la inducción matemática, cuantifica sobre propiedades, por lo que no puede formularse en una lógica de primer orden (que toma sólo objetos como valores $d \epsilon$ sus variables), sino en una de segundo. Ahora bien, el teorema de Löwenheim-Skolem, que Quine considera en profundidad, afecta sólo a la lógica de primer orden, mientras que, por otra parte, los axiomas de Peano pueden formularse como estructura categórica en segundo orden. Así, la limitación que representa semejante teorema y su amenaza para la rcducción ontológica de Quine no se presentarían, si los axiomas de Peano se entienden como si estuvieran formulados en segundo orden (Tharp 1971a, p. 153).

En el mismo contexto, Quine insiste, una y otra vez, en que la reducción a números naturales de toda teoría consistente de 
primer orden, por virtud del mismo teorema, no debería tomarse como una reducción verdadera, lo que desea mostrar mediante la falta de una función sustitutiva que correlacione viejos y nuevos objetos. Sin embargo, esa distinción entre reducciones verdaderas y reducciones triviales no está justificada en absoluto (ibid., p. 156). Sin duda toda esta problemática surge del hecho de la falta total de criterios en Quine para elaborar una clasificación de los distintos tipos de reducciones ontológicas, que debería quizá apelar a una clasificación de los tipos de objetos y podría llevar a resultados similares a los de Russell y sus símbolos incompletos. Pero ello, a su vez, rompería dos de los presupuestos vitales para Quine: i) la misma relatividad ontológica, que exige una tercera teoría para explicar toda reducción de una teoría a otra; ii) la tesis de que ser un objeto es sólo ser el valor de una variable, lo que hace muy difícil distinguir entre objetos reales y aparentes (o subsistentes). De ahí la debilidad del argumento de la reductio ad absurdum (véase más arriba).

Otra forma de resaltar tal debilidad, que surge al considerar teorías autorreductoras, consiste en señalar ejemplos triviales. Como adujo ya Quine, puede probarse que el conjunto de números mayores que 16 constituye el dominio de un modelo de la aritmética, pero difícilmente podríamos admitir que con ello hemos autorreducido (económicamente) la aritmética en un sentido ontológicamente relevante. Por otra parte, cuando, en el mismo argumento de la autorreducción (que parece, sin embargo, extensible a toda reducción), consideramos una teoría $U$ reducida a otra $V$, siendo, pues, $U$, también la teoría de fondo, se plantea inmediatamente el problema de la existencia de lo que desaparece con la reducción, es decir, de lo que no parece que necesite existir, en el sentido corriente de reducción económica.

En efecto, difícilmente podemos mostrar que sólo una parte de $U$ existe siendo así que desde el punto de vista de $U$, que es la teoría de fondo, toda ella existe. Tendríamos que situar- 
nos desde el punto de vista de $V$, aun cuando parece que la ontología de $U$ esté presupuesta en $V$. En palabras de Tharp (1971a, p. 158):

Lo que resulta claramente demostrado es que, si se está considerando la adopción de un universo $U$, se puede sin ulterior compromiso asumir $V$ y obtener una interpretación de la forma de la teoría de $U$ en $V$. Puesto que podemos justamente asumir que en general $V$ se define y se conoce sólo en términos de $U$, ¿cuál es el propósito de aceptar $V$ ? Seguramente no es más seguro aceptar $V$ que $U . V$ no es más claro que $U$. Parece que la economía, en el sentido rechazado arriba, sería el único motivo.

Podemos considerar la dificultad para el caso de los infinitesimales. Como veíamos más arriba Weierstrass logró su "eliminación" mediante la afinación de los conceptos del análisis. Con ello, sin embargo, pareció eliminar lo que no existía. De ahí la dificultad de aplicar la función sustitutiva y señalarlos como objetos correlacionados con sus sustitutos. En este caso, sin embargo, hubo conservación de funciones y un aumento de la seguridad y la claridad. Sin embargo, con la definición conjuntista de los infinitesimales por A. Robinson (donde de nuevo nos salimos del marco de la autorreducción) hay también reducción, mediante la preservación de funciones, aunque no hay eliminación por ningún lado, y la economía es dudosa.

Por todo ello me parece que sin una ontología no puramente relativista es imposible hablar de forma consistente de reducción. Como Frege y Russell la tenían, pudieron permitirse el lujo de combinar la reducción y la explicación con la falta de eliminación, como sucede en el caso de su célebre definición del número de una clase. Por el mismo motivo, rebasaron el marco de Dedekind y Peano no sólo porque, como von Neumann o Zermelo, fueron capaces de construir una progresión en términos de clases (o conjuntos), sino sobre todo porque aportaron un marco general donde el número de una clase, el concepto de número y la clase de los números pueden ser 
perfectamente distinguidos. Claro que para ellos, precisamente porque partían de una base ontológicamente firme, semejante reducción tenía valor epistemológico y proveía, pues, nuevo conocimiento, al menos en el sentido de que proveía un marco más general, con conexiones más amplias, donde insertar el mundo de los números, pero sin que éstos perdieran su estatus anterior como realidades ineliminables.

Por eso precisamente parece que la tesis quineana de que basta con el mantenimiento de la estructura para la aceptación de una reducción dada es insuficiente. Y ello porque las teorías no tienen, en su formulación originaria, sólo propósitos lógicos, sino también toda una serie de nexos con otras teorías, tanto desde el punto de vista lógico como desde el empírico (o "teórico"). Como ha señalado Chihara, tales conexiones, en Quine, han de entenderse como si estuvieran presupuestas por la teoría de fondo que nos hace posible la reducción; pero entonces: " ¿Son los nexos proporcionados por la teoría de fondo irrelevantes para los 'fines originarios' de la teoría? Si es así, sería un hecho sorprendente" (1973a, p. 127). Así, si entendemos que ciertas presuposiciones ontológicas de una teoría forman de algún modo parte de la teoría de fondo, entonces parecería que diversas teorías de fondo aportarían visiones muy diferentes de cada teoría y, por tanto, de cada reducción. Más aún, puesto que a menudo Quine sugiere que la teoría de fondo no es más que la teoría incorporada en el lenguaje ordinario, y éste depende de las personas, o de las comunidades de hablantes, ello hace muy difícil rehuir las claras conexiones pragmáticas. Por tanto, o admitimos claramente las conexiones diversas que una teoría tiene con otras, a través de la teoría de fondo usada como instrumento de la reducción, o no tiene mucho sentido hablar de reducción.

Quine ha insistido mucho en que el mantenimiento de la estructura es lo único importante para una reducción (con las mejoras relevantes, la función sustitutiva, etc.). Ya sabemos que, en contraposición a Frege-Russell, eso lo ha llevado a re- 
chazar que necesitemos una progresión determinada, apoyada en ciertas mejoras epistemológicas, para los usos prácticos, al menos en puridad. Pero incluso si nos limitamos a la pura reducción ontológica, el que cierta reducción sirva los fines de cierta teoría anterior no garantiza la eliminabilidad a menos que introduzcamos argumentos de algún tipo, y no sólo el de la eliminabilidad práctica, a riesgo de no poder distinguir entre reducciones que eliminan lo problemático y reducciones que simplemente sustituyen unos objetos por otros, sin más pretensiones. En realidad, aun aceptando el criterio quineano, lo único que garantiza una reducción dada es que cierta ontología, vista desde una 6ptica determinada (la de la teoría de fondo) es formulable en otra, pero eso no parece, por sí mismo, tener nada que ver con la eliminación en el sentido ontológico del término. Hablar de eliminación parece presuponer un punto de vista (una teoría) permanente, y no una simple comparación de teorías desde una tercera, pues el compromiso ontológico parece funcionar sólo dentro de una teoría dada, ya que sólo en una teoría tiene sentido hablar de variables de cuantificación. Chateaubriand ha tocado el problema con relación a la reducción de números a conjuntos (citado en Chihara, 1973a, p. 133).

Si en ignorancia de la reducibilidad del número a la teoría de conjuntos se hubiesen adoptado ambas teorías y establecido los números y los conjuntos como entidades diferentes, entonces una vez que nos demos cuenta de que la teoría de números es reducible a la teoría de conjuntos se ve que no es necesario establecer los números y los conjuntos como entidades diferentes. Quine desea decir que, en consecuencia, podemos repudiar los números en favor de los conjuntos. Pero eso es confundente $[\ldots]$ lo que repudiamos es nuestra errónea $\longrightarrow$ al menos innecesaria - suposición de que al adoptar [...] [ambas teorías] habíamos establecido los números como entidades diferentes de los conjuntos. La ontología de los números no resulta repudiada en absoluto; se muestra sólo que es una parte de la ontología de los conjuntos. 
Aplicando, una vez más, esta idea a la eliminación de los infinitesimales por Weierstrass, tendríamos que lo que caracterizaría la verdadera reducción sería la función sustitutiva, pero lo único que se habría mostrado es que una ontología (la de los infinitesimales) es formulable en otra, y eso, a su vez, parece decir que después de todo los infinitesimales no han sido "eliminados". Así que las exigencias que hacen posible la eliminación obran en contra de ella misma. Lo que la última cita parece añadir es, simplemente, lo que señalaba yo más arriba: que si queremos distinguir entre varios tipos de eliminación habremos de hacerlo a través de una clasificación de las reducciones, lo cual parece presuponer una ontología absoluta y no relativa.

El ejemplo de la eliminación de las clases por Russell es de nuevo relevante, sobre todo porque usualmente se la considera como una reducción ontológica. Valga la descripción de Chihara, que es especialmente iluminadora (1973a, pp. 134-135):

En PM, para cada clase $a$, hay muchas funciones proposicionales con a como su extensión; sin embargo la teoría sin clases no asocia una única función proposicional con cada clase. Y no resulta obvio cómo se especificaría precisamente la requerida función sustitucional. Pero incluso aunque la exigencia de la función sustitutiva no se satisfaga, se admite generalmente que la teoría sin clases muestra la forma en que podemos prescindir de las clases en favor de las funciones proposicionales [...] Así, la cuestión de si puede especificarse una función sustitutiva que relacione clases con funciones proposicionales parece claramente irrelevante.

Es una pena que el autor no se percate de que la misma idea, como habíamos visto en la sección anterior, es perfectamente aplicable a todos los símbolos incompletos russellianos, que surgicron del paradigma de las teorías de las descripciones. Entendido así, el texto citado no hace más que señalar la incohcrencia implícita en la exigencia de una función sustitutiva. Por formularla de manera especialmente escandalosa, 
podríamos decir: de acuerdo con Quine, podemos eliminar los objetos de una teoría si y sólo si los mantenemos en otra, la teoría de fondo, al tiempo que la misma estructura es preservada en la teoría final. Y, puesto que siempre es necesaria una teoría de fondo y una teoría final, la reducción quineana no es reducción de ningún tipo. Una vez más parece que el pez relativista se muerde la cola.

Los problemas de Quine comenzaron cuando trató de eliminar, por trivial, una reducción que, sin embargo, parecía cumplir con el requisito de la preservación de la estructura: la pitagorización subyacente en el teorema de Löwenheim-Skolem. La consecuencia fue que la modelización no era una condición suficiente; se requería, además, la función sustitutiva que preservara, de alguna forma, los objetos por reducir, aunque fuese en la teoría de fondo. Eso es como decir que el mantenimiento de la estructura es, en realidad, una mera condición necesaria entre otras y, después de todo, no otra cosa es lo que pensaron Frege y Russell, para quienes tampoco la modelización era suficiente. Si pensamos en que, además, la estructura por sí misma tampoco garantiza el que los modelos sean isomorfos y que, por tanto, caben interpretaciones no estándar, entonces no parece que la crítica de Quine al modelo de FregeRussell rebase mucho el punto de vista formalista.

Quizá la predilección quineana por la reducción de los números a conjuntos - que, como hemos visto, no puede justificarse alegando una mayor seguridad, ya que el concepto de conjunto no es menos problemático que el de número- pueda explicarse con argumentos de carácter pragmático. Así, si la teoría de conjuntos nos provee un contexto más amplio y potente, parece mejor escogerla como marco para que la ontología de los números se manifieste y desarrolle. Steiner ha señalado, sin embargo, que ello supone, precisamente para un pragmatista como Quine, cierta incoherencia: "Esta postura presupone que podemos separar las cuestiones ontológicas de las epistemológicas; que podemos obtener una ganancia ontológica que 
no sólo no sea una ganancia epistemológica, sino que incluso sea una pérdida" (1975a, p. 75). Desde luego con ello vamos a parar al mismo tipo de consideraciones que hacíamos respecto al logicismo clásico; pues para sus partidarios la reducción a las clases proveía sin duda un fundamento más seguro, en la medida en que, prescindiendo ahora de las paradojas, al menos reconvertía las verdades de la aritmética en verdades lógicas.

Pero el problema ahora es más profundo: hablar de un marco más amplio y potente hace - de nuevo- referencia a la conexión con otras teorías. El ejemplo de Steiner es instructivo. Reducir la teoría de números a la de conjuntos sería como cambiar una red de computadoras, de poca potencia aunque de seguridad garantizada, por otra mucho más potente y susceptible de llevar a cabo operaciones más complejas, que nos permite, de paso, conectarnos con otras redes y operaciones. El precio que debemos pagar sería, sin embargo, el afrontar el riesgo de errones. La decisión debería ser, pues, estratégica, no meramente táctica.

Sin embargo, la analogía tiene sus limitaciones, al menos en la medida en que, aunque para Quine la reducción nos permite prescindir de la vieja teoría, no obstante podríamos conservar la antigua, como los viejos computadores, para ciertas tareas. Así, si de lo que se trata es sólo de conservar la parte de teoría de conjuntos que "traduce" las verdades más simples de la aritmética —aquellas que se dimanan de los axiomas de Peano-, entonces parece que estaríamos confiando en un fragmento de teoría de conjuntos apoyándonos paradójicamente en los viejos objetos, que se han mostrado más seguros desde el punto de vista de la consistencia. Steiner protesta de nuevo desde la epistemología: "¿lo sabríamos si hipotéticamente nos libráramos de la carga del conocimiento numérico, que es nuestro acceso al 'modelo estándar' de los axiomas de Peano? No hay, pues, un sentido claro en el que la teoría de conjuntos no pueda asumir la tarea de la teoría de números desde un punto de vista pragmatista" (1975a, p. 76). Sin duda la maniobra 
tendría toda la apariencia de un juego de manos: sería como hablar un segundo idioma a sabiendas de que podemos volver al original en cualquier momento, con el agravante de que no sólo esos momentos serían los problemáticos, sino de que nuestra comprensión del contenido por transmitir mediante el segundo idioma dependería del originiario, desde el que hemos aprendido el segundo. Tengo mis dudas acerca de si esto es reformulable en términos de la relatividad ontológica y el lenguaje - la teoría- de fondo.

Llevando el ejemplo del fragmento "numérico" de la teoría de conjuntos hasta el final, si imaginamos un matemático que opere con él en ignorancia de los axiomas de Peano que le servirían de base, entonces nuestro teórico podría incluso sospechar inconsistencias en su modelo de trabajo, y lo haría precisamente porque el fundamento epistemológico del que podría haber disfrutado, de contar con aquella base, ha desaparecido. Consideraciones similares llevan a Steiner a negar definitivamente que haya un sentido claro en el que incluso una teoría de conjuntos limitada pudiese llevar a cabo el trabajo de la teoría de números (1975a, p. 80). Pero a mí me interesa destacar de nuevo aquí lo de la falta del contexto que supondrían los nexos con otras teorías.

Si admitimos que la gigantesca construcción de Bourbaki ha provisto una nueva fuente de seguridad, no sólo de belleza, para la matemática, entonces estamos obligados a responder a la pregunta: isu seguridad proviene sólo del hecho de que la construcción ha sido hecha "hacia atrás", gozando ya de las teorías por reconstruir de manera conjuntista? $\mathrm{O}$ a esta otra: ¿cabe imaginar un desarrollo de la historia de la matemática y de la lógica en el que se hubiese podido comenzar por la base conjuntista? La respuesta a esta segunda pregunta parece claramente negativa pues la matemática nació de sus aplicaciones, pero ello no nos obliga a responder afirmativamente a la primera. Parece también claro que la sistematización presupuesta en semejante reconstrucción lo es precisamente porque 
ha arrojado luz, desde el punto de vista del marco global, sobre muchos resquicios pertenecientes a las fronteras entre diversas teorías matemáticas y, por tanto, también sobre la unidad general.

Podemos concluir, con Steiner, que lo que él llama logicismo ontologico conduce al siguiente dilema: o admitimos la reducción de números a conjuntos, mediante las definiciones explícitas relevantes, con el riesgo epistemológico consiguiente, o la interpretamos como una simple maniobra mediante la cual redefinimos los axiomas de Peano de manera conjuntista (en términos de clases), en cuyo caso implícitamente añadimos una serie infinita de nuevas proposiciones — verdades - a nuestro sistema. Yo creo que en ambos casos la ganancia está sólo en lo que vengo llamando el marco global general y el aumento en conexiones de nuestra teoría. Es cicrto que la teoría de números es más segura que la teoría de conjuntos, pero, salvo dentro de una noción sumamente estrecha de "teoría", la seguridad no es lo prioritario, sobre todo si, como es el caso del logicismo —o similares_ la prioridad absoluta era de carácter filosófico.

El propio Steiner ha introducido con postcrioridad nuevas ideas que vienen a coincidir con mi intento de dar importancia al marco global del desarrollo de una teoría. Sc trata de su idea de la "explicación matemática", en la senda del paralelismo progresivo actual entre la matemática y las ciencias empíricas, uno de cuyos mentores es precisamente Quine. La idea general es simple y se apoya en la idea indefinida - pero obvia- de "familia" de entidades (1978a, p. 143):

Mi postura explota la idea de que para explicar el comportamiento de una entidad se deduce ese comportamieńto de la esencia o naturaleza de la entidad. Entonces el controvertido concepto de una propiedad esencial de $x$ (una propiedad que $x$ tiene en todos los mundos posibles) no tiene uso alguno en matemáticas, dada la suposieión de que todas las verdades de las matemáticas son necesarias. En lugar de "esencia", hablaré de "propiedades 
características", con lo cual quiero decir una propiedad única para una entidad o estructura dada dentro de una familia a dominio de tales entidades o estructuras [...] Tenemos así una noción relativa, puesto que una entidad dada puede ser parte de un número de familias o dominios diferentes. Incluso en un dominio único, las entidades pueden caracterizarse multívocamente [...] Mi propuesta es que una prueba explicativa hace referencia a una propiedad característica de una entidad o estructura mencionada en el teorema, tal que desde el punto de vista de la prueba es evidente que el resultado depende de la propiedad.

Lo que puede hacerse con tal idea en la práctica no parece ser mucho, salvo superar la simple relación teorema-prueba y sustituirla por la existente entre un conjunto de teoremas y un conjunto de pruebas, a través de una "deformación" (nuevo concepto indefinido, que recuerda ahora el principio geométrico de dualidad y por tanto la definición implícita), la cual mostraría que cada una de las pruebas "explica" su correspondiente teorema y, con él, la conducta de un "objcto matemático" subyacente. Así, un mismo objeto podría ser caracterizado según perteneciera a diferentes familias.

Es obvio el nexo de tales ideas con el estructuralismo en boga en filosofía de la matemática, pero aquí no puedo abordarlo. Lo que sí quisiera es usarlas para mostrar un nuevo tipo de crítica al concepto quineano de reducción. La tesis de Steiner al respecto es que la preservación de la estructura a través de un modelo no es, como afirma Quine, criterio suficiente para la reducción, si admitimos su idea de la explicación matemática: "Dos pruebas de un teorema pueden diferir en valor explicativo. Y una explicación matemática articulada en una teoría puede ser destruida cuando la teoría es modelada en otra. Estoy por tanto inclinado a no considerar la modelización como algo suficiente para la reducción en matemáticas" (1979a, p. 134). Así, para Steiner puede mostrarse que la explicación matemática puede decidir cuestiones referentes a las distintas valoraciones que podemos hacer de la reducción matemática. 
La idea esencial es que ciertas reducciones son más fértiles que otras (Steiner no usa esta expresión pero la tentación es irresistible), puesto que insertan la entidad reducida en un marco que abre todo un nuevo campo de conexiones. Por ejemplo: "la interpretación de los números complejos como puntos en un plano o vectores abre nuevas perspectivas matemáticas; la interpretación de las fracciones como pares ordenados no hace tal cosa" (1979a, p. 139). En efecto, al interpretar los complejos como vectores, podemos hablar de propiedades como la "longitud" y la "dirección", así como reinterpretar viejos resultados de forma que se abran nuevas posibilidades e incluso se descubran nuevos teoremas.

Por el contrario, Quine defiende que precisamente lo que añaden de distinto las nuevas reducciones ha de ser considerado como "esiguales" (don't cares), puesto que no afectan el isomorfismo básico al rebasar las funciones que esperamos de las viejas entidades. Para Steiner son precisamente tales cuestiones las que pueden permitirnos escoger entre diversas reducciones y, por tanto, defender el valor reductivo de una de ellas (ibid., p. 140):

nuestro ejemplo de los números complejos muestra que no todas las tales cuestiones son "esiguales" [don't cares]. En el caso de los números racionales la "longitud" o "dirección" de tales números [es] carente de consecuencias tanto tras la reducción a pares ordenados como antes. Pero el concepto de longitud o dirección es tan fructífero cuando se aplica a los números complejos que la reducción en este caso parece casi revelar propiedades de los números complejos que estaban previamente ocultas - como la expiicación atómica de las leyes de los gases revela propiedades de los gases (el grado de interacción entre los átomos, etc.) que estaban previamente ocultas.

Es obvio que, como también nota Steiner, la situación podría reconducirse a una distinción entre dos clases de reducciones: aquellas que tendrían mero valor económico y las que, al depender de una nueva familia de conceptos, ofrecerían un nuevo 
campo, siendo éstas sin duda las preferibles. El criterio es dudoso por cuanto, desde el punto de vista operativo, las reducciones son como las definiciones: toda opción tiene sentido sólo desde el punto de vista de nuestros propósitos concretos. Ello me permite terminar con una breve reflexión sobre el tema general de la reducción y la eliminación.

Si parece razonable hablar de varios tipos de reducción, lo mismo debería suceder con la noción, mucho más oscura, de eliminación, sin que ello tuviera que llevarnos a una ontología relativista. Benacerraf retomó en su célebre 1965a, que aquí no puedo analizar, algunos de estos temas, con lo cual contribuyó a un intento de situar la posible distinción entre reducción y eliminación en un marco no necesariamente relativista. Yo creo que el mayor interés radicaba precisamente en el problema de la eliminación de lo construido, y por tanto en el tema de las diferentes descripciones (matemáticas o no) de una misma entidad. Por eso sería interesante considerar su intento, así como las críticas de que ha sido objeto, en el marco de la explicación matemática, si no precisamente steineriano, sí haciendo referencia a la construcción global a que pueden someterse los números, como demostro por ejemplo Russell insertando su reducción de los números a clases en el marco de una teoría de los cardinales previa a la de los ordinales (y las progresiones). ${ }^{8}$ Con ello fue mucho más allá que Frege y me resulta difícil ver la razón por la que Quine no se sirvió de tal construcción global para ilustrar los problemas de su propio criterio de reducción.

\section{Agradecimientos}

Al aparecer este texto, que constituye el segundo de mis dos trabajos presentados en el simposio sobre "La existencia y el conocimiento de las entidades matemáticas" (el primero apareció en el número 68 de esta revista), quisiera agradecer aquí

B He desarrollado estas ideas en mi 1991b. 
tanto la invitación en sí misma a participar, como las valiosas observaciones que numerosos asistentes hicieron tras mis exposiciones. En contra de mi idea original, lamento no haber podido discutirlas en detalle en nuevas notas, cosa que hubiera alargado aún más estos ya de por sí extensos textos. Quiero también agradecer la amabilidad con la que el profesor Quine accedió a leer este artículo, así como las observaciones que me hizo al respecto, tanto en persona como por correspondencia.

\section{BIBLIOGRAFÍA}

Benacerraf, P., 1965a, "What Numbers Could not Be", en Benacerraf y Putnam (comps.), 1983a, pp. 272-294.

Benacerraf, P. y H. Putnam (comps.), 1983a, Philosophy of Mathematics, Cambridge University Press.

Blasco, J. Ll., 1974a, "Compromiso óntico y relatividad ontológica", en Aspectos de la filosofia de W.V. Quine, Universidad de Valencia, 1976.

Carnap, R., 1950a, "Empiricism, Semantics and Ontology", en Meaning and necessity, University of Chicago Press, 1956.

Chihara, C.S., 1973a, Ontology and the Vicious Circle Principle, Cornell University Press, Ithaca (Nueva York).

Dipert, R.R., 1982a, "Set-theoretical Representations of Ordered Pairs and their Adequacy for the Logic of Relations", Canadian Journal of Philosophy, no. 12, pp. 353-374.

Parsons, C., 1965a, "Frege's Theory of Numbers", en C. Parsons 1983a, pp. 150-175.

—, 1971a, "Ontology and Mathematics", en C. Parsons 1983a, pp. 37-62.

- 1983a, Mathematics and Philosophy, Cornell University Press, Ithaca (Nueva York).

Quine, W.V., 1940a, Lógica matemática, trad. cast. J. Hierro, Revista de Occidente, Madrid, 1972.

_-, 1943a, "Notas sobre existencia y necesidad", en T. M. Simpson (ed.), Semántica filosófica, trad. cast. I. Carballo, Siglo XXI, Buenos Aires, 1973, 
_ 1948a, "Acerca de lo que hay", en Desde un punto de vista lógico, trad. cast. M. Sacristán, Ariel, Barcelona, 1962.

- 1951a, "Dos dogmas del empirismo", en Desde un punto de vista lógico, trad. cast. M. Sacristán, Ariel, Barcelona, 1962.

_ 1951b, "Carnap's Views on Ontology", Philosophical Studies, no. 2, pp. 65-72.

__, 1952a, Los mélodos de la lógica, trad. cast. J.J. Acero y N. Guasch, Ariel, Barcelona, 1981.

_- 1958a, "Hablando de objetos", en La relatividad ontológica y otros ensayos, trad. cast. M. Garrido y J.Ll. Blasco, Tecnos, Madrid, 1974.

—, 1960a, Palabra y objeto, trad. cast. M. Sacristán, Ariel, Barcelona, 1968.

—_ 1963a, Set Theory and its Logic, Harvard University Press, Cambridge (Mass).

—, 1964a, "Ontological Reduction and the World of Numbers", en The Ways of Paradox and other Essays, Random House, Nueva York, 1966.

__ 1966a, "On Ordered Pairs and Relations", en Selecled Logic Papers, Random House, Nueva York, pp. 110-113.

_-, 1969a "Relatividad ontológica", en La relatividad ontológica $y$ otros ensayos, trad. cast. M. Garrido y J.Ll. Blasco, Tecnos, Madrid, 1974.

Rodríguez Consuegra, F., 1989a, "Russell's Theory of Types, 19011910: its complex origins in the unpublished manuscripts", Hist. Phil. Log., no. 10, pp. 131-164.

— 1989b, "The Origins of Russell's Theory of Descriptions According to the Unpublished Manuscripts", Russell, no. 9, pp. 99-132.

- 1990a, "Bertrand Russell and Bradley's Ghost: Evolution and Significance of Russell's Views Concerning Relations" (en prensa).

- 1990b, "El impacto de Wittgenstein sobre Russell: últimos datos y visión global" (en prensa).

_ 1991a, The Mathematical Philosophy of Bertrand Russell: Origins and Development, Birkhäuser/Basilea/Boston/Berlín.

__ , 1991b, "Númcros, objetos y estructuras", Crítica. Revista IIispanoamericana de Filosofia, vol. 23, no. 68, pp. 7-86.

Steiner, M., 1975a, Mathematical Knowledge, Cornell University Press, Ithaca (Nueva York). 
—, 1978a, "Mathematical Explanation”, Philos. Studies, no. 34, pp. 135-151.

, 1979a, "Quine and Mathematical Reduction", en R.W. Shahan y C. Swoyer (comps.), Essays on the Philosophy of W.D. Quine, The University of Oklahoma Press.

Tharp, L.H., 1971a, “Ontological Reduction”, Jrn. Phil., no. 68, pp. 151-164.

Recibido: 28 de octubre de 1991. 
I try to show here how, when and why Quine's doctrine of ontological reduction evolved, and also the links which can be traced between that doctrine, Russell's view of reduction (or construction) as "new knowledge", and Benacerraf's ideas. In addition, I discuss some relevant criticisms of Quine's position, mainly those by Tharp, Chihara and Steiner.

After a section trying to unify Quine's main theses as proceeding from the paraphrastical methods of Russell's theory of descriptions, I hold that Quine's evolution towards a deeper sort of ontological reduction was a result of his attempts to clarify the difficulties of his original explanation of mathematical reduction. Thus, the doctrine of mathematical reduction in Word and Object, which was an important source of inspiration to Benacerraf and others, was only a first draft where Quine's pragmatism shows the diverse reconstructions of the same mathematical concepts to be equivalent and also all correct, despite their possible incompatibility with the only condition to play the relevant roles. The general context then was one of increasing ontological relativity, but the underlying identification of reduction and elimination was - I think so- the main idea. A similar position was held in Set Theory and its Logic, where Quine put the emphasis on the fact that a model for arithmetic is provided simply by introducing a set-theoretical interpretation which would be able to preserve truth.

However, in 1964 a turning point appears: now there is a distinction between two different ontological reductions, one attempting only to replace certain entities by constructions playing their roles, the other attempting, also to eliminate the original entities as well, by showing their dispensability. The reason was that Quine realized that through the Löwenheim-Skolem theorem we should accept that any theory can be reduced to natural numbers, which seemed to him trivial, but met his previous criterion for acceptable reductions. Then he introduced the need for a "proxy function" admitting as arguments all the objects of the universe of the first theory, taking values in the universe of the second theory, and having to be formulated in a third "inclusive" theory. As this condition is not met by the "reduction" inferred from the Löwenheim-Skolem theorem, it was not a "true" ontological reduction. 
Yet the problem was that if we have to distinguish between ontological reduction and mere "modelization", then we concede for the entities of the first theory - those to be eliminated- the status of objects, so that no ontological gain is achieved at all. I think that when Quine delved deep into his ontological relativity in 1969 he was simply reacting to this problem. Thus, his identification between the third theory we need to set up the proxy function, and the "background theory" underlying any translation between two languages, seems to me to be the main result, despite Quine's attempts to show that the old objects to be eliminated are only accepted "strategically" -for the sake of the argument-, which seems to me rather unconvincing. 